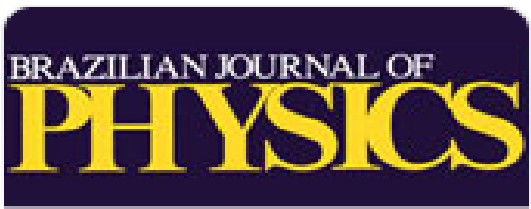

Brazilian Journal of Physics

ISSN: 0103-9733

luizno.bjp@gmail.com

Sociedade Brasileira de Física

Brasil

Flores-Mena, J. E.; Juárez Morán, L. A.; Díaz Reyes, J.

Electronic Equipment Proposal to Improve the Photovoltaic Systems Efficiency

Brazilian Journal of Physics, vol. 41, núm. 1, mayo, 2011, pp. 29-37

Sociedade Brasileira de Física

Sâo Paulo, Brasil

Available in: http://www.redalyc.org/articulo.oa?id=46421597005

How to cite

Complete issue

- More information about this article

Journal's homepage in redalyc.org



Scientific Information System

Network of Scientific Journals from Latin America, the Caribbean, Spain and Portugal Non-profit academic project, developed under the open access initiative 


\title{
Electronic Equipment Proposal to Improve the Photovoltaic Systems Efficiency
}

\author{
J. E. Flores-Mena · L. A. Juárez Morán · J. Díaz Reyes
}

Received: 3 July 2010 / Published online: 14 April 2011

(C) Sociedade Brasileira de Física 2011

\begin{abstract}
This paper reports a new technique proposal to improve the photovoltaic systems. It was made to design and implement an electronic system that will detect, capture, and transfer the maximum power of the photovoltaic (PV) panel to optimize the supplied power of a solar panel. The electronic system works on base technical proposal of electrical sweeping of electric characteristics using capacitive impedance. The maximum power is transformed and the solar panel energy is sent to an automotive battery. This electronic system reduces the energy lost originated when the solar radiation level decreases or the PV panel temperature is increased. This electronic system tracks, captures, and stores the PV module's maximum power into a capacitor. After, a higher voltage level step-up circuit was designed to increase the voltage of the PV module's maximum power and then its current can be sent to a battery. The experimental results show that the developed electronic system has $95 \%$ efficiency. The measurement was made to $50 \mathrm{~W}$, the electronic system works rightly with solar radiation rate from 100 to $1,000 \mathrm{~W} \mathrm{~m}^{-2}$ and the $\mathrm{PV}$ panel temperature rate changed from 1 to $75^{\circ} \mathrm{C}$. The main advantage of this
\end{abstract}

J. E. Flores-Mena $(\bowtie) \cdot$ L. A. Juárez Morán Facultad de Ciencias de la Electrónica, Benemérita Universidad Autónoma de Puebla, C. P. 72570, Puebla, Puebla, México

e-mail: eflores@ece.buap.mx

L. A. Juárez Morán

e-mail: luisjumo13@hotmail.com

J. Díaz Reyes

CIBA-IPN Tlaxcala, Ex-Hacienda de San Juan Molino,

Km. 1.5, Tepetitla, Tlaxcala, 90700, México

e-mail: jdiazr2010@yahoo.com electronic system compared with conventional methods is the elimination of microprocessors, computers, and sophisticated numerical approximations, and it does not need any small electrical signals to track the maximum power. The proposed method is simple, fast, and it is also cheaper.

Keywords Maximum power point tracking • Photovoltaic module $\cdot$ Electric sweeping $\cdot$ Solar energy

\section{Introduction}

The photovoltaic (PV) cells are electronic devices that transform the visible light into electrical energy of direct current [1], see Fig. 1. The generated current $\left(I_{\mathrm{g}}\right)$, output voltage $\left(V_{\mathrm{c}}\right)$, serial resistance $\left(R_{\mathrm{s}}\right)$, flight resistance $\left(R_{\mathrm{f}}\right)$, output current $\left(I_{\mathrm{c}}\right)$, and the output power $\left(P_{\mathrm{c}}\right)$ are related by the following equation:

$$
\begin{gathered}
P_{\mathrm{c}}=V_{\mathrm{c}}\left\{I_{\mathrm{g}}-I_{0}\left(\exp \left[\frac{q\left(V_{\mathrm{c}}+I_{\mathrm{c}} R_{\mathrm{s}}\right)}{k_{\mathrm{B}} T}\right]-1\right)\right. \\
\left.-\frac{V_{\mathrm{c}}+I_{\mathrm{c}} R_{\mathrm{s}}}{R_{\mathrm{f}}}\right\},
\end{gathered}
$$

where $I_{0}$ is leakage current of diode, $q$ is the electron charge, and $k_{\mathrm{B}}$ is Boltzmann constant.

The PV module is composed by 36 cells electrically connected in cascade; its output voltage is $19 \mathrm{~V}$. Its output current is around 1-3 A, and its output power is about 17-90 $\mathrm{W}$ depending on the manufacturer [2]. The PV module has one electrical condition where it supplies output maximum power, this condition has a maximum current $\left(I_{\mathrm{m}}\right)$ and a maximum voltage $\left(V_{\mathrm{m}}\right)$ [3]. 


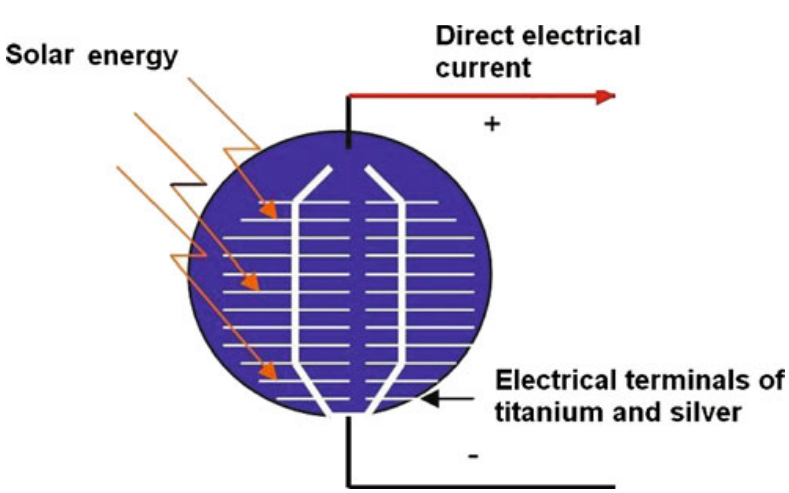

Fig. 1 Photovoltaic solar cell

The PV module is designed to be connected to an automotive battery, and its electrical characteristic $I_{\mathrm{g}}$, $V_{\mathrm{c}}, V_{\mathrm{m}}$, and $P_{\mathrm{c}}$ are determined at $25^{\circ} \mathrm{C}$ and $1,000 \mathrm{~W} \mathrm{~m}^{-2}$ of solar radiation, but in real operation conditions the radiation level is variable, see Fig. 2, and also the operation temperature of the module can increase up to 1.75 times more than the nominal temperature [4], then its output voltage can be lower than the battery voltage, Fig. 3; therefore, its current does not charge the battery and then the module energy is lost. Such condition reduces the module power because the maximum power point changes continually. The electronic equipment should be designed to detect the maximum power of the PV module and to transfer it to the battery. Its operation consists of the electrical sweeping of the module's I-V characteristic function [4].

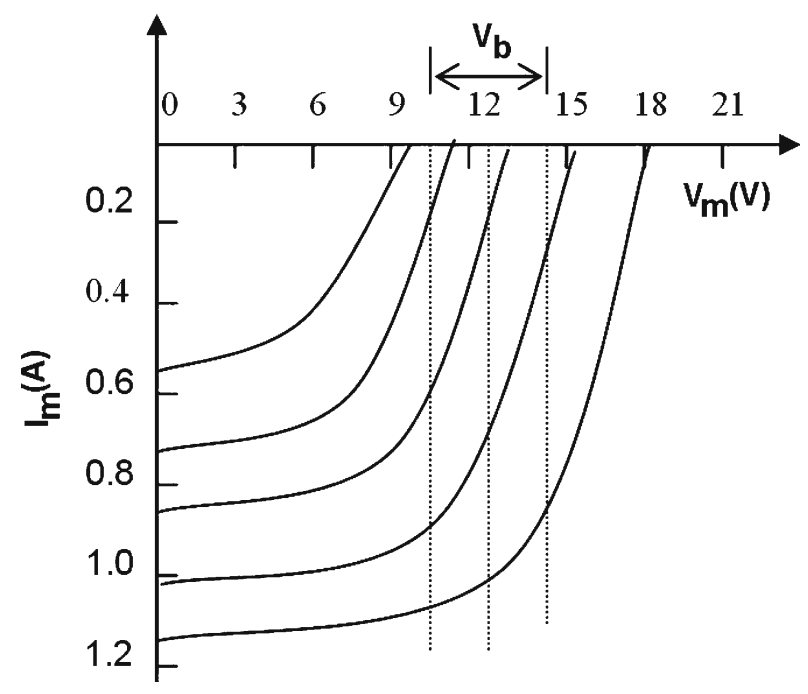

Fig. 2 I-V curves of the PV panel with variable irradiation

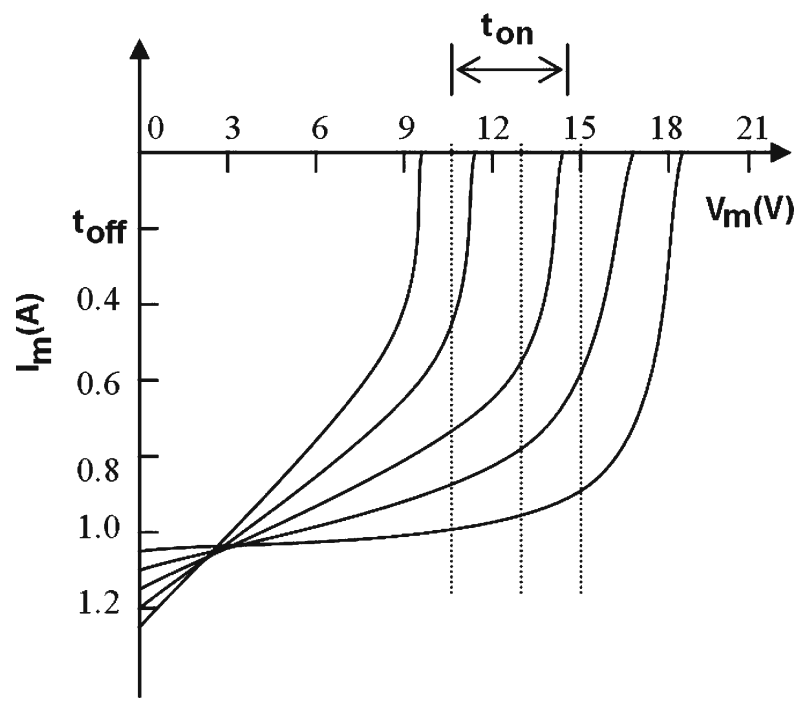

Fig. 3 The PV panel output voltage is decreased for temperature increasing

When the temperature of the PV module is increased or when the irradiation level is very low, the voltage of the PV module is reduced and the PV module's current cannot charge the automotive battery, because the module's maximum power voltage becomes lower than the battery's voltage. So, the power of the PV module is lost. This technical problem can be eliminated by designing a maximum power point tracker (MPPT) electronics circuit. Some MPPTs have been developed using different techniques.

Ladsman [5] compared the power of two PV module curves and changed the PV module's voltage to generate oscillation around the maximum power of the PV module. Another method to locate the maximum power of the PV module was proposed by Arcidiacono et al. [6], wherein they used a small triangle periodical signal to generate oscillations around the maximum point over the current-voltage curve. The same authors also developed a sophisticated mathematics algorithms [6] using derivative function of V-P curve to determine the MPPT. Bucciarelli [7] used a personal computer and microprocessors to track the PV module MPP. de Beruete and Serrano [8] located the PV module's maximum power, modulating the current signals of the module to generating electrical oscillation around the PV module's maximum power point. Goncalvez et al. [9] located the maximum power controlling the PV module's current and the battery current. Chung [10] located the MPPT of the panel, modulating a small sinusoidal signal and controlling the maximum variation of the PV module's voltage. Some 
a)

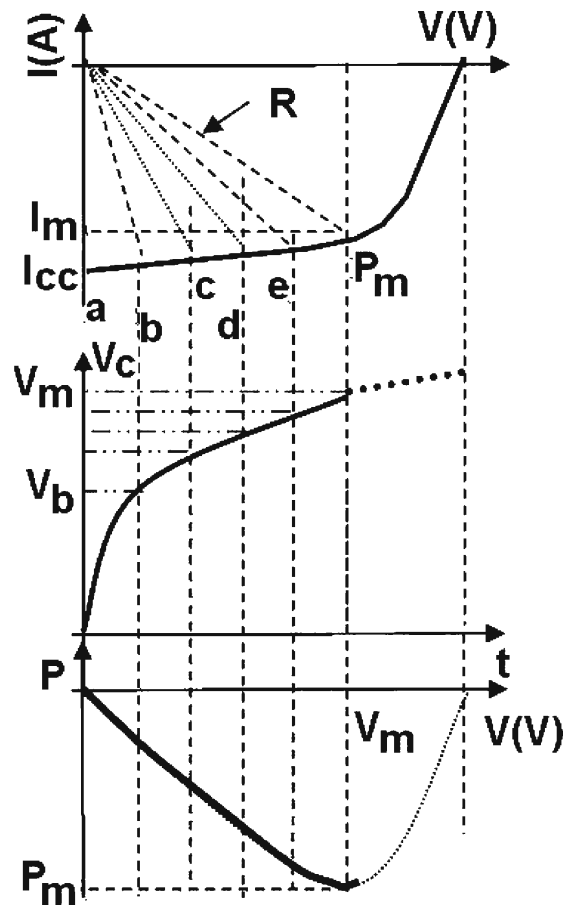

Fig. 4 It is showed the proposal of the electrical sweeping of the PV module current-voltage curve

of these methods are sophisticated and complex, but they are also very expensive some times.

Here, one proposes a new technical design to develop an MPPT, which detects the maximum power of the PV module and after transfers it into an electrical load or automotive battery. The proposed MPPT works on the base of the electrical sweeping of the PV module's current-voltage characteristics curve. The proposal of an electrical sweeping technique of the PV module's I-V curve (Fig. 4) is implemented using analogical and digital electronic devices to detect the MPP, after the maximum power voltage is increased and its current is sent to battery. The developed technique here is simple, fast, and it has no computer or numerical problem and it is cheaper.

\section{Proposed Electronic System}

The electrical sweeping technique was proposed to detect the maximum power point (MPP) of the PV module, using a capacitor, inductor, and electronic switches by a CMOS power transistor coupled to the module. The capacitor is charged by the current module, and then the current and voltage of the photovoltaic generator are sampled and processed determining the power while it is going through $P_{\mathrm{m}}$. The charge and discharge of the capacitor is achieved by an electronic switch using power transistors with a metal oxide semiconductor (MOS) connected in cascade with the capacitor to the PV module. This technique works by means of electrical auto regulation of the PV module and the variable impedance of the capacitor. The transistor is driven by an electronic circuit, which detects when the $P_{\mathrm{m}}$ is reached, see Fig. 5.

At the beginning, the switch is opened and the module is in the open circuit condition, the voltage at point $\mathrm{A}$ is the maximum value given by the module and corresponds to the voltage of the open circuit $\left(V_{\text {ca }}\right)$ and the capacitor $C$ is discharged. When the switch is closed, the module sends the maximum current $I_{\mathrm{cc}}$ to the capacitor, this effect corresponds to the condition of a short circuit because the capacitor is discharged; the capacitor begins to charge and the module is going through the maximum power curve point. And at this moment, the control circuit blocks the switch and the module's maximum power is stored in the capacitor; therefore, the voltage-current characteristic curve of the module is swept in an analogical form.

The sweeping of the current-voltage characteristic curve of the PV generator can be executed by using the proposed method, which sweeps point by point all the values from $I_{\mathrm{sc}}$ to $V_{\mathrm{ca}}$, going through $P_{\mathrm{m}}$. The lost energy coming from the module is eliminated by means of the technique proposed because of the energy is stored in the capacitor. When the electronic circuit detects the module maximum power the switch is opened and discharges the capacitor energy into the

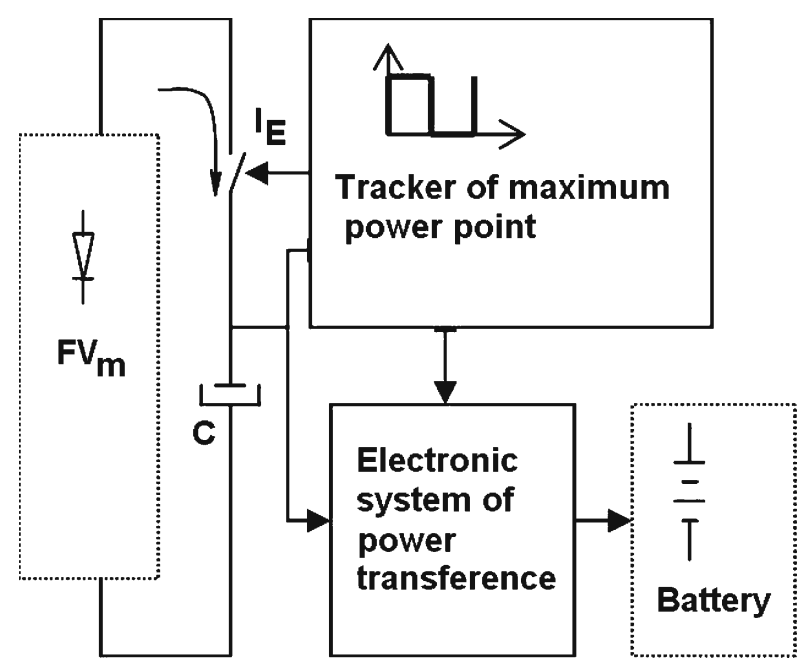

Fig. 5 Blocks diagram of proposed electronic system 
battery beginning the capacitor charging process. The electronic system illustrated in Fig. 5 is integrated by two important stages: (a) an electronic circuit that is continuously detecting the maximum power of the solar module, this circuit was designed to work with great rates of incident light from 100 to $1,000 \mathrm{~W} \mathrm{~m}^{-2}$. It also works with broad temperature range from 0 to $70^{\circ} \mathrm{C}$, and (b) the second one is an electronic circuit that transform the output power of the PV module and it works from 0 to $70^{\circ} \mathrm{C}$ increasing the $\mathrm{PV}$ module voltage and sending the PV module energy to the battery, this electronic circuit is designed to work from 1 to $50 \mathrm{~W}$.

\subsection{Control Electronic Circuit to Detect the Maximum Power}

The proposed electronic system is mainly composed by two stage, the first one is an electronic circuit that uses the MC1494L analogical multiplier circuit to determine the power, and the second one is a logic circuit composed by several integrated circuits to generate the signal control which frequency was calibrated to $3,000 \mathrm{~Hz}$, a point detector and a comparator circuit were also used to detect the maximum power [11], the output signal of this stage is shown in Fig. 6.

\subsection{Design of Electronic System \\ of Energy Transference}

Due to maximum power energy of the PV module is instantaneously stored into an electrolytic capacitor, so that, this energy must be transferred to the battery or electronic equipment that must be working. Then, one proposes a commutation circuit to transform and transfer the PV panel maximum power; this electronic system increases the voltage level until it is higher than the battery voltage so that the PV module current can be flowing to the battery [12]. The electronic circuit of energy transference was designed to a modulator circuit of variable wide pulse, which increases the voltage of maximum power of the PV module so that its current can flow to the battery, see Fig. 7.

\subsubsection{Designing Equations}

When the output of the electronic system's maximum power detection (see Fig. 7) presents a high-level voltage $(15 \mathrm{~V})$, the power transistor $(T)$ is fixed to a saturation condition during a short time period of about $1 \times 10^{-3} \mathrm{~s}$, in this time the current from the capacitor $\left(C_{\mathrm{A}}\right)$ flows by the inductor and the stored energy in the capacitor is discharged, but at the same time it is stored in the inductor. When the output of the electronic system's maximum power detection presents a lowlevel voltage $(0 \mathrm{~V})$ in the gate of the $T$, the transistor stops its work and the current does not flow; then, a voltage level is generated in the self inductor and therefore the inductor output voltage is increased, so the output voltage of the PV module maximum power is greater than the battery voltage. Then, the module energy instantaneously stored in the capacitor is transferred to the battery. This electronic technique allows the transformation of the voltage power from low to high, which can then be transferred to the battery. The designing equation of a commutation electronic circuit is connected with the input voltage $\left(V_{\mathrm{i}}\right)$, output voltage $\left(V_{0}\right)$, and the dropping voltage between the source and drainer of the power transistor $\left(V_{\mathrm{st}}\right)$, the turn-on time $\left(t_{\mathrm{on}}\right)$ and the turn-off time $\left(t_{\mathrm{off}}\right)$ of the electronic

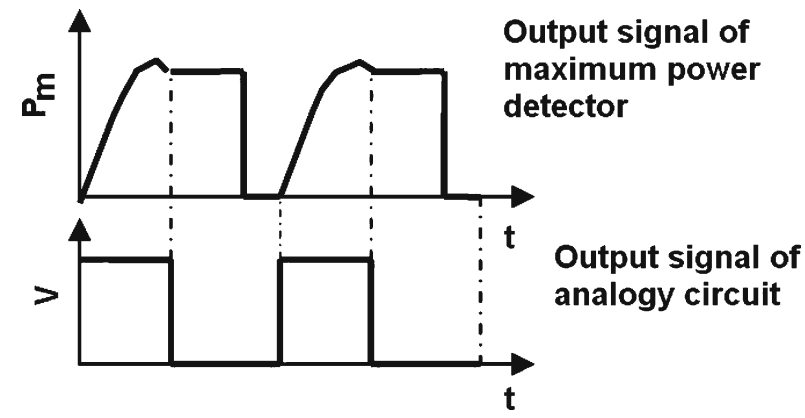

Fig. 6 Theoretical waveforms of electronic circuit to detect the maximum power

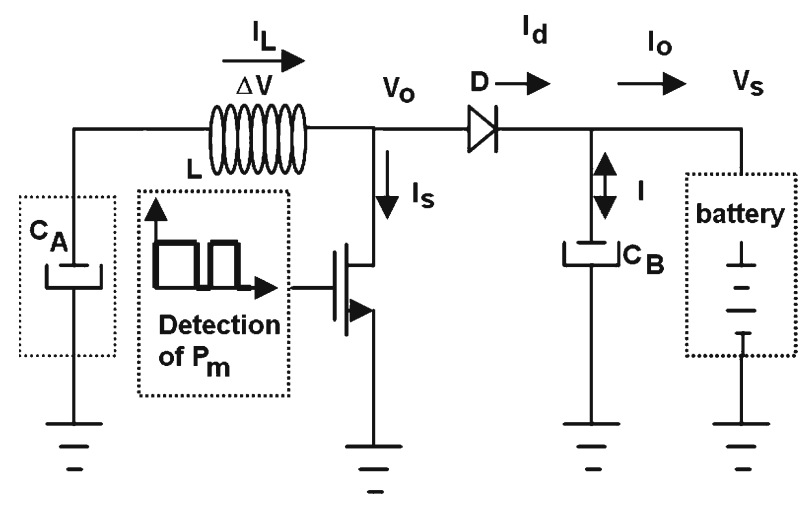

Fig. 7 Block diagram of proposed transference circuit 
circuit's timer. All these variables are related in the following equation [13].

$\left(\frac{V_{0}-V_{\mathrm{i}}}{L}\right) t_{\mathrm{off}}=\left(\frac{V_{\mathrm{i}}-V_{\mathrm{st}}}{L}\right) t_{\mathrm{on}}$.

The electrical capacitance $(C)$ and the inductance ( $L$ ) can be determined by the output current $\left(I_{0}\right)$, the ripple voltage $\left(\Delta V_{0}\right)$, the output voltage $\left(V_{0}\right)$, and the frequency $(f)$ of the timer circuit, which are related by the following equations:

$C=\frac{I_{0}\left(V_{0}-V_{\mathrm{i}}\right)}{V_{0} f \Delta V_{0}}$,

$L=\frac{2.5 V_{\mathrm{i}}^{2}\left(V_{0}-V_{\mathrm{i}}\right)}{f I_{0} V_{0}^{2}}$.

\subsubsection{Designing Characteristics}

The commutation circuit was designed to work at a 3$\mathrm{KHz}$ frequency, the rate of its input voltage is from 8 to $17 \mathrm{~V}$, the supplied voltage rate ranges from 12 to $16.5 \mathrm{~V}$, the voltage rise is $50 \mathrm{mV}$, the output current is $3.3 \mathrm{~A}$, and the output power is $50 \mathrm{~W}$. A high efficiency is required. Here, it proposes more than $90 \%$, therefore, power electronic devices with metal oxide semiconductor (MOS) technologies were used. The output voltage of energy transference circuit is higher than the module voltage, which was connected at the input of the transference electronic circuit. Then, the electrical power with low-level voltage that had been stored into the capacitor connected in cascade with the photovoltaic module can be transformed to the same power but with great voltage and low output current. And then, one can be sure that the module's photovoltaic output is transmitted to the battery. And so, the lost energy of the PV module, which was originated by low radiation solar level or high PV module temperature, can be eliminated. Fig. 7 illustrated a lineal electronic commutation regulator which is integrated electronically using a MOSFET power transistor of $15 \mathrm{~A}$ and $75 \mathrm{~V}$, an inductor of $250 \mathrm{mH}$, an electrical capacitor of $4,700 \mu \mathrm{F}$, a rectifier diode with Schottky barrier of $6 \mathrm{~A}$ and $50 \mathrm{~V}$, and an electronic circuit that detects the maximum power point of the solar module. The output voltage value of this circuit depends on the delay time in which the maximum power was detected; therefore, the power transference circuit is driven by voltage pulses supplied by the maximum power point tracker. With this proposed system, it is possible to increase the efficiency of the MOSFET power transistor by using a Schottky diode [13]. In this case, the elected MOSFET power transistor, when it is working in full conduction, presents low electrical resistance, which is about $0.1-0.2 \Omega$; also, this transistor only needs from 200 to $250 \mathrm{nA}$ in its gate to work rightly [14]. So that when the output current of developed electronic system is around $4 \mathrm{~A}$ and the output voltage is about $15 \mathrm{~V}$, then the lost power is only $0.75 \mathrm{~W}$, also in the Schottky diode with the same characteristics the lost power is only $0.5 \mathrm{~W}$. For the above technical reasons, the great input power is transferred to the output circuit, and therefore its efficiency is increased. The output voltage level is regulated to control the commutation time of conduction and no conduction of a power transistor. When high-level voltage is presented on the transistor gate, this going to full conduction condition, then the electrical current energy that had been stored into the capacitor flows throw the inductor and it is stored into the self inductor. When the voltage is approximately zero on the transistor gate this does not work, and the magnetic field drastically changes in direction, this electrical condition creates in the inductor a voltage level that has an opposite direction, so that the current's continues flowing throw the inductor in the same direction, therefore the output voltage is equal to the input voltage of the transference circuit plus the generated voltage of the inductor. Thus, the transference electronic circuit works in increasing the output voltage. Figure 8 shows the waveforms of electrical signals of the Fig. 7 circuit.

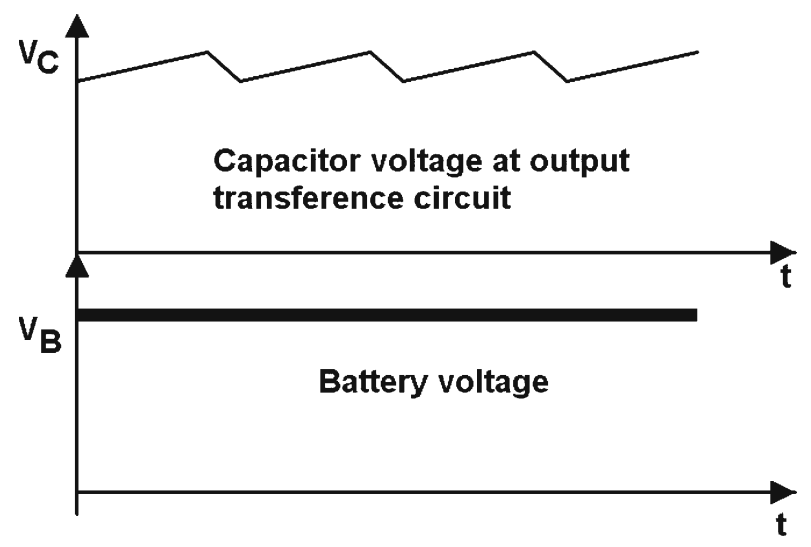

Fig. 8 Theoretical waveforms of energy transference circuit 


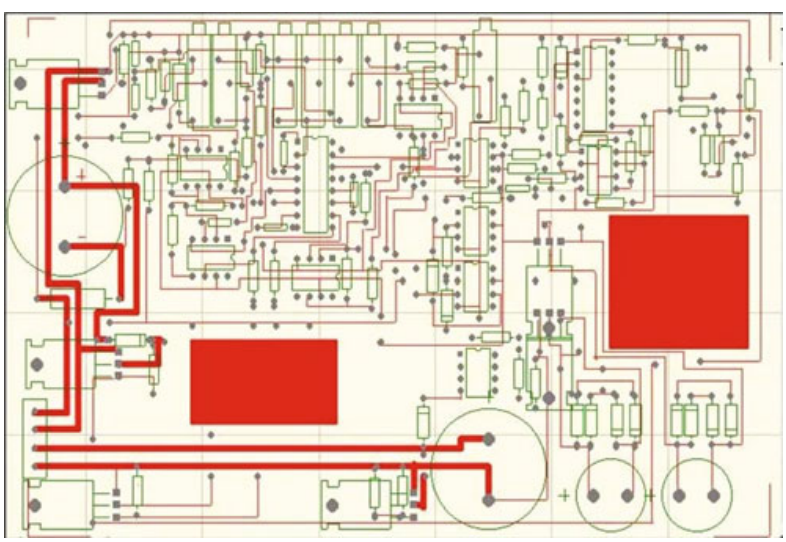

Fig. 9 Printed circuit board

\section{Electronic System Implementation}

Integrated circuits with MOS technology were used to reduce the energy lost. In order to determine the PV module's electrical power, the analogical multiplier MC1494L was selected [15]. The electrical signals of the current and voltage were driven using analogically integrated circuits MC407, the oscillation frequency was fixed using the timer MC555. For the logic circuit, several MOSFET gates connected with the comparator LM311 were used to detect the maximum power and in order to drive the power were using the transistors MCN3055 and MCP2955, due to their being present in low electrical resistance of about $0.1 \Omega$ at full conduction and $0.2 \mathrm{~V}$ between drainer and source of the transistor [16]. Also, to reduce the power lost, the Schottky

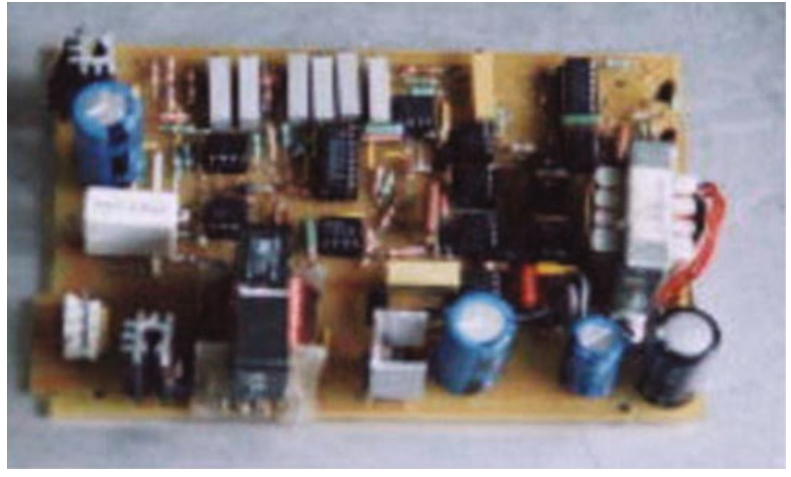

Fig. 10 Electronic system implemented to optimize the solar panel energy barrier diode was used. A printed circuit board parts layout was designed and developed to fix the electrical elements and integrated electronic circuits, see Fig. 9, and the developed electronic system is shown in Fig. 10.

\section{Electrical Signals Measurements}

In order to make the measurements, a photovoltaic system (PVS) was implemented, which was integrated by the following elements: three PV modules of $17 \mathrm{~W}$, $1.1 \mathrm{~A}$, and $17 \mathrm{~V}$ manufactured in laboratory, one automotive battery of $60 \mathrm{~A}-\mathrm{h}$ and $12 \mathrm{~V}$, one electrical resistance of $100 \mathrm{~W}$, the developed electronic circuit, one solar simulator of variable radiation that performs from 50 to $1,000 \mathrm{~W} \mathrm{~m}^{-2}$, and a resistive load of $3.6 \Omega, 150 \mathrm{~W}$. The electrical waveforms, the current, the voltage, and the power were measured in different sections of the electronic circuit being developed.

\section{Waveform Measurement in Maximum Power Detection Circuit}

To prove that the proposed electrical swept technique works properly, the output waveforms from the maximum power detection electronic circuit and the logical circuit were measured; the obtained results are illustrated in Fig. 11. These measurements were made

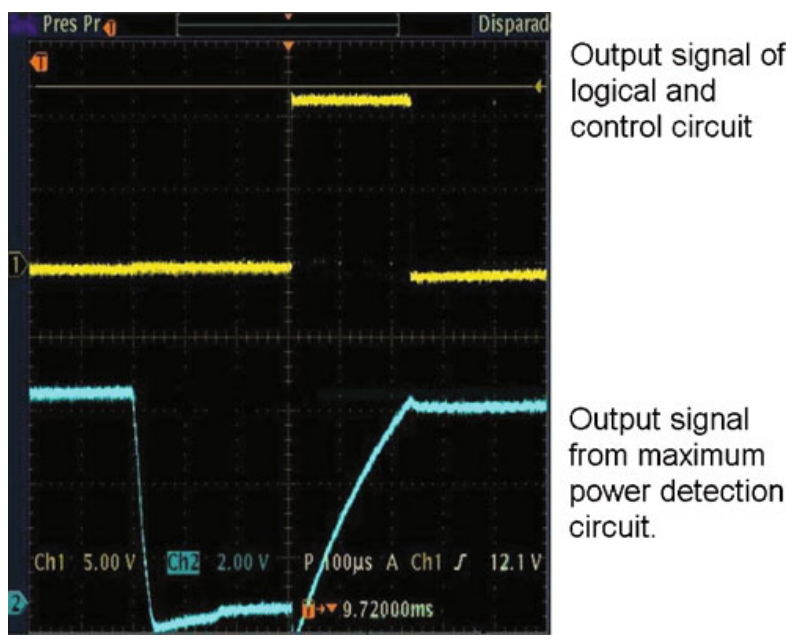

Fig. 11 Output waveforms obtained from maximum power detection circuit 


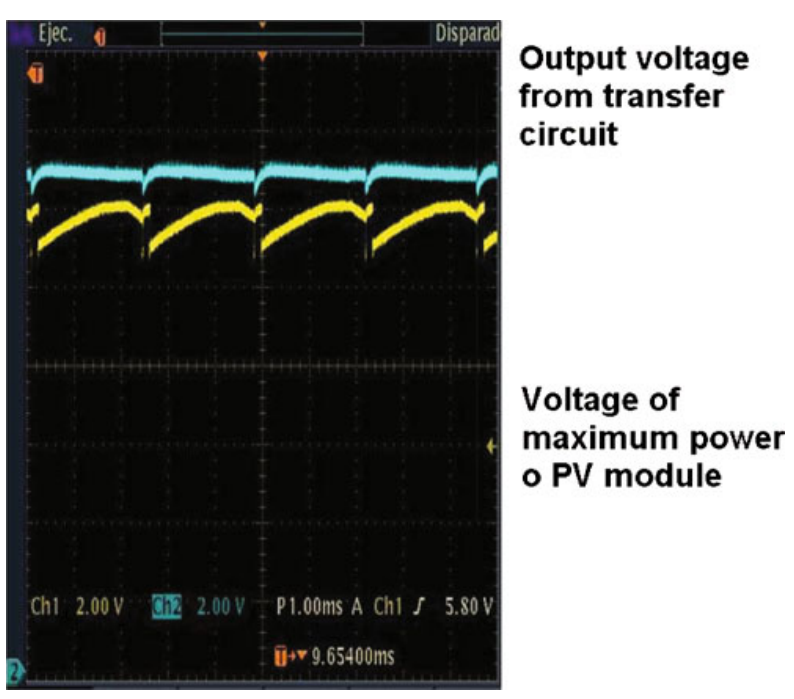

Fig. 12 Output waveforms from energy transfer circuit

using three PV modules connected in parallel, and the incident power of the solar simulator was $750 \mathrm{~W} \mathrm{~m}^{-2}$. Also, the different output waveforms from the energy transference circuit to the battery were measured, see Fig. 12. This was made to verify that the technical design is right and the electronics circuit of this section

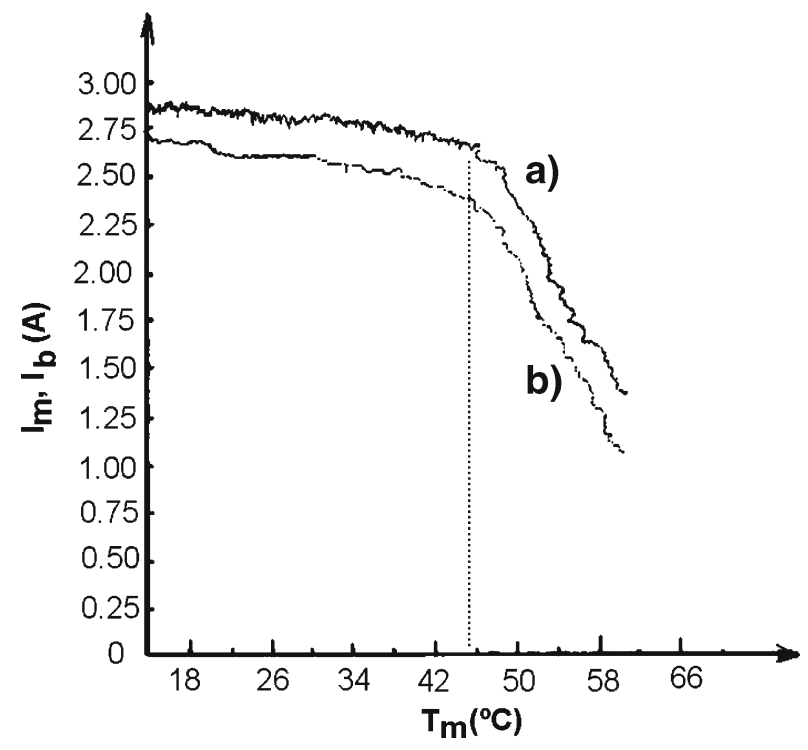

Fig. 13 The PV module current versus temperature curve $a$ ) and the output current from developed electronic system to battery curve $b$ ) are working in accordance with the proposed design criteria.

\subsection{Current Measurement}

In a PV system composed of a 60-A-h battery, developed electronic system, two PV modules of $27 \mathrm{~W}$, and three electric lamps, the incident light power was calibrated at $925 \mathrm{~W} \mathrm{~m}^{-2}$. Output current curves versus PV module temperature were measured, see Fig. 13. The output current from the circuit developed in the battery was measured, where four technical pins were used to avoid mistakes during this process [11]. Also in the same process, the PV module's current was measured at the input of the developed electronic system when the radiation level was calibrated at $925 \mathrm{~W} \mathrm{~m}^{-2}$. To compare the value of the PV module's current when it is directly connected to the battery with that of the current of the PV module at the output of the developed electronics system, both variables were simultaneously measured. The results are shown in Fig. 14. The electrical current $\left(I_{\mathrm{m}}\right)$, voltage $\left(V_{\mathrm{m}}\right)$, and power $\left(P_{\mathrm{m}}\right)$ were measured from the PV module, and the same electrical variables $I_{\mathrm{b}}, V_{\mathrm{b}}$, and $P_{\mathrm{b}}$ were also measured after the developed electronic system at the battery input to determine the electronic system efficiency. The results are presented in Table 1.

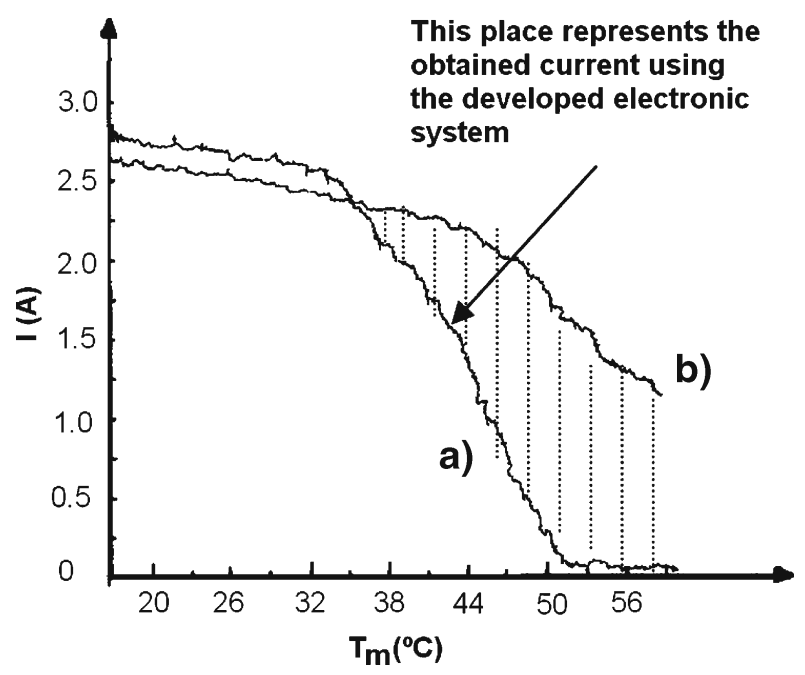

Fig. 14 The PV module's output current versus temperature in curve $a$ ) and output current from electronic system versus temperature of the PV module in to the battery curve $b$ ) 


\begin{tabular}{|c|c|c|c|c|c|c|c|}
\hline \multirow{26}{*}{$\begin{array}{l}\text { Table } 1 \text { Experimental results } \\
\text { of current, voltage, and } \\
\text { power that were measured } \\
\text { from the designed electronic } \\
\text { system at its input and output }\end{array}$} & $T_{\mathrm{m}}\left({ }^{\circ} \mathrm{C}\right)$ & $V_{\mathrm{m}}(\mathrm{V})$ & $V_{\mathrm{b}}(\mathrm{V})$ & $I_{\mathrm{m}}(\mathrm{A})$ & $I_{\mathrm{b}}(\mathrm{A})$ & $P_{\mathrm{m}}(\mathrm{W})$ & $P_{\mathrm{b}}(\mathrm{W})$ \\
\hline & 14 & 14.47 & 13.66 & 3.49 & 3.48 & 50.47 & 47.85 \\
\hline & 17 & 14.45 & 13.66 & 3.48 & 3.47 & 50.30 & 47.37 \\
\hline & 19 & 14.43 & 13.57 & 3.47 & 3.46 & 50.00 & 47.29 \\
\hline & 20 & 14.40 & 13.68 & 3.45 & 3.43 & 49.85 & 46.92 \\
\hline & 21 & 14.36 & 13.68 & 3.42 & 3.42 & 59.52 & 46.70 \\
\hline & 25 & 14.32 & 13.69 & 3.41 & 3.41 & 49.26 & 46.66 \\
\hline & 27 & 14.24 & 13.73 & 3.40 & 3.35 & 48.69 & 46.54 \\
\hline & 32 & 14.18 & 13.76 & 3.38 & 3.31 & 47.92 & 45.70 \\
\hline & 36 & 14.10 & 13.81 & 3.35 & 3.18 & 47.21 & 44.85 \\
\hline & 40 & 13.99 & 13.83 & 3.24 & 3.10 & 45.27 & 43.03 \\
\hline & 43 & 13.94 & 13.85 & 3.21 & 3.04 & 44.80 & 42.10 \\
\hline & 46 & 13.90 & 13.87 & 3.10 & 2.92 & 42.84 & 40.66 \\
\hline & 48 & 13.88 & 13.88 & 3.03 & 2.85 & 41.75 & 39.55 \\
\hline & 49 & 13.79 & 13.88 & 2.92 & 2.74 & 39.88 & 38.10 \\
\hline & 52 & 13.61 & 13.78 & 2.85 & 2.67 & 38.75 & 36.79 \\
\hline & 53 & 13.48 & 13.77 & 2.82 & 2.61 & 37.84 & 35.90 \\
\hline & 54 & 13.34 & 13.64 & 2.70 & 2.53 & 36.00 & 34.50 \\
\hline & 56 & 13.21 & 13.58 & 2.61 & 2.40 & 34.48 & 32.60 \\
\hline & 57 & 13.16 & 13.49 & 2.54 & 2.32 & 33.15 & 31.30 \\
\hline & 59 & 13.00 & 13.46 & 2.50 & 2.27 & 32.50 & 30.60 \\
\hline & 60 & 12.94 & 13.39 & 2.42 & 2.22 & 31.13 & 29.72 \\
\hline & 62 & 12.86 & 13.23 & 2.37 & 2.19 & 30.45 & 29.06 \\
\hline & 64 & 12.72 & 13.20 & 2.31 & 2.13 & 29.35 & 28.11 \\
\hline & 65 & 12.65 & 13.16 & 2.24 & 2.05 & 28.30 & 26.90 \\
\hline & 67 & 12.50 & 13.14 & 2.12 & 1.92 & 26.50 & 25.20 \\
\hline
\end{tabular}

\section{Discussion of Results}

From waveforms shown in Fig. 12 to around the maximum power and control signal, one can see if they are similar to theoretical waveforms, see Fig. 6, and therefore the electronic circuits of the electronic system to detect the PV maximum power are properly working. Where the power waveform shows the electric sweeping of the voltage current curve of the PV module is made by the capacitor charge/discharge process. On the basis of the energy transference circuit waveforms, from Fig. 11, they are equal to a proposed theoretical waveform, which are shown in Fig. 7, where one can see that the electronic system output voltage is higher than the PV module voltage and then this indicates that the PV module's current is flowing to the battery although the solar radiation level on the PV module is low.

From the current curves versus PV module temperature and the current from the electronic system output, which are reported in Fig. 13, it can be seen that the current of the PV module's maximum power (curve a) is greater than the output current (curve b) of the developed electronic system for the same temperature, this situation is due to the efficiency of the electronic system. The current curve a from Fig. 14, which was obtained with the PV module was directly connected to the battery, here one can see when the PV module temperature increase more than $35^{\circ} \mathrm{C}$ the $\mathrm{PV}$ module's current decreases faster to zero when the temperature is greater than $49^{\circ} \mathrm{C}$; however, when the developed maximum power track is used and it is connected between battery and PV module, then the PV module current (curve b) is approximately the same value for the same temperature $49^{\circ} \mathrm{C}$. This situation indicates that the developed electronic system works very well. The experiment results in Table 1 have shown that the efficiency of this electronic system is $95 \%$.

\section{Conclusions}

The experimental results show that the detection and transference of the module maximum power by the proposal method of electrical sweeping was right. So, the electronic system continuously detects the maximum power point and also it works with different radiance level from 100 to $1,000 \mathrm{~W} \mathrm{~m}^{-2}$ and the temperature of the PV module from 0 to $72^{\circ} \mathrm{C}$.

The presented method does not generate oscillations. It does not need to determine the derivative of the power and it does not require to measure of the slop sign of the power voltage curve. The experimental 
results presented in this paper have proven that the designed method and implemented electronic circuit can be used to resolve the problem of the PV module's power loss due to the temperature change and low irradiance level, and optimize the PV module's energy. The PV module's output current can still flow to the battery even though the PV module's output voltage is lower than the battery's voltage due to the $\mathrm{PV}$ module's temperature increment above $49^{\circ} \mathrm{C}$. The experimental results show that the electronic system proposed has $95 \%$ efficiency. The proposed method was implemented with simple electronic devices, it is very stable, reliable, secure, and more economical than other known methods. In future investigations, it will be possible to improve the electronic circuit performance and to increase its output power.

Acknowledgements The authors thank the IPN of Mexico for the academic support and CONACyT (project 42790) of México for their financial support. This work was partially supported by VIEP-BUAP (project 3/I/ING09).

\section{References}

1. M.A. Green, in Solar Cells Operating Principles, Technology and Device Applications (Prentice-Hall, Englewood Cliffs, 1982)

2. H.J. Novel, in Semiconductor and Semimetal Solar Cells VII (Academic, London, 1975)

3. I.Y. Pals, in Hand Book of Photovoltaic Systems (PrenticeHall, Englewood Cliffs, 1992)

4. P.J. Vega, V. Ponomaryov, Maximum power detection electronic circuit for photovoltaic module. International Journal, Telecommunications and Radio Engineering Edit 56(1), 126134 (Begell House, New York, 2001)

5. E.E. Landsman, in Maximum Power Trackers for PhotovoltaicArrays. 13th IEEE Photovoltaic Specialists
Conference, Washington, D.C., USA, June 1978. pp. 9961000

6. V. Arcidiacono, S. Corsi, L. Lambri, in Maximum Power Point Tracker for Photovoltaic Power Plants. 15th IEEE Photovoltaic Specialists Conference, Orlando, FL, USA, 1982. pp. $507-512$

7. L.L. Bucciarelli, B.L. Grossman, E.F. Lyon, N.E. Rasmussen, The energy balance associated with use of a maximum power tracer in a $100 \mathrm{KW}$-peak power system. Proc. IEEE, New York, 1980. pp 523-527

8. I. de Beruete, L. Serrano Iribarnegaray, in Circuito de Mando para el Seguimiento del Punto de Máxima Potencia, Mundo Electrónico, Energía Solar Fotovoltaica (Marcombo, España, 1986). pp. $147-150$

9. M. Goncalves Wanzeller, R. Nazareno Cunha Alves, J. Viana da Fonseca Neto, W. A. dos Santos Fonseca, Current control loop for tracking of maximum power point supplied for photovoltaic array. IEEE Trans. Instrum. Meas. 53(4), 1304-1310 (2004)

10. H. Shu-Hung Chung, K.K. Tse, S.Y. Ron Wui, M.C. Mok, M.T. Ho, A novel maximum power point tracking technique for solar panels uning a SEPIC or Cuk converter. IEEE Trans. Power Electron. 18(3), 717-724 (2003)

11. J. Vega-Perez, V. Ponomaryov, L. Nino-de-Rivera, Electronic system for power optimization of photovoltaic generator. Int J Elec Waves and Electronic Systems 8(7-8), 12-15 (2003). ISSN 1560-4128

12. J. Vega-Perez, V. Ponomaryov, L. Nino-de-Rivera, in Transfering Electronic System of Solar Module Power. Proceedings of the IEEE, Guanajuato Mexico Section, 2nd International Workshop on Random Fields Modeling and Processing in Inhomogeneous Media, Guanajuato, Mexico, 27-29 November 2002. pp 67-69

13. M.H. Rashid, in Electrónica de Potencia (Prentice-Hall, Englewood Cliffs, 1999)

14. S. Wang, in Fundamentals of Semiconductor Theory and Device Physics (Prentice-Hall, Englewood Cliffs, 1989)

15. Motorola Data Book, Linear Integrated Circuits (Cambridge University Press, Cambridge, 1179). pp. 6,60-6,99

16. J. Vega-Perez, V. Ponomaryov, L. Nino-de-Rivera, Solar module power capture and transference electronic system. Journal of Telecommunications and Radio Engineering 56(4-5), 80-87 (Begell House, New York, 2001). ISSN 00402508 